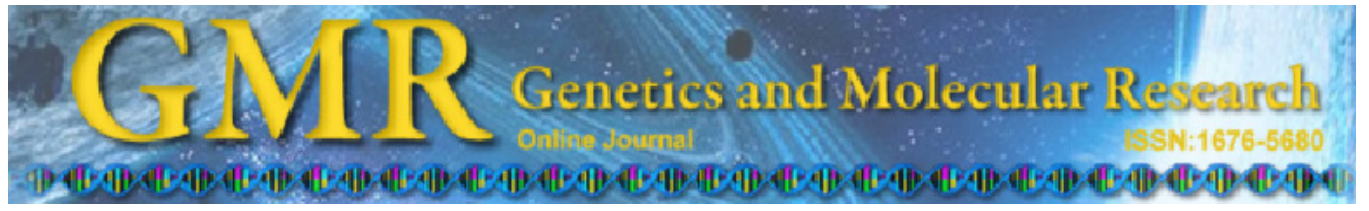

\title{
Molecular mapping of genes for opposite leafing in maize using simple-sequence repeat markers
}

\author{
Y.Q. Tan ${ }^{1}$, C.X. Xie ${ }^{2}$, H.Y. Jiang ${ }^{1}$, H. Ye ${ }^{1}$, Y. Xiang ${ }^{1}$, S.W. Zhu ${ }^{1}$ and B.J. Cheng ${ }^{1}$ \\ ${ }^{1}$ Institute of Life Science, Anhui Agricultural University, Hefei, China \\ ${ }^{2}$ Chinese Academy of Agricultural Sciences, Beijing, China \\ Corresponding author: B.J. Cheng \\ E-mail: beijiucheng@ahau.edu.cn
}

Genet. Mol. Res. 10 (4): 3472-3479 (2011)

Received January 4, 2011

Accepted August 31, 2011

Published November 22, 2011

DOI http://dx.doi.org/10.4238/2011.November.22.3

\begin{abstract}
Maize with opposite phyllotaxy (OP) and also initiating ears in opposite pairs is an aberrant mutant and also precious material for maize breeding and plant evolution studies. Mapping and identifying the markers closely linked to genes for the OP trait are essential for cloning the gene and marker-assisted selection in breeding. We established H14D, a near-isogenic line of the OP trait with $\mathrm{H} 53$ genetic background. We found that the OP trait is regulated by two independent dominant genes with mutually complementary relations, named $O p p-1$ and $O p p-$ 2. Screening of seven simple-sequence repeat (SSR) markers among the 105 pairs of SSR primers showed polymorphism between the inbred lines H14D and H53. The polymorphic SSR markers were then used to determine linkage with the trait in an $\mathrm{F}_{2}$ population with 441 progeny, suggesting that SSR marker umc2094 in the Bin2.01 region is linked with $O p p-1$ at $6.7 \mathrm{cM}$, and bnlg1831 in Bin2.06 is linked with $O p p-2$ at $6.1 \mathrm{cM}$. Further investigation showed that bnlg1092 and umc1028 are linked to $O p p-1$ and $O p p-2$ genes, with genetic distances of 12.2 and 1.9 $\mathrm{cM}$. It was also found that the four SSR markers flank the two OP genes, respectively. These results will be useful for marker-assisted selection breeding of OP maize and will also strengthen the basis for cloning of the opposite leafing gene.
\end{abstract}

Key words: Linkage group 2 (LG2); NIL; Opposite leafing genes; $O p p-1$ and $O p p-2$; Simple-sequence repeat markers 


\section{INTRODUCTION}

Decussate phyllotaxy is commonly found in the dicotyledon group, but never in the grasses which belong to the monocotyledon groups (Moore, 1964). Maize initiates leaves singly, alternating from one side to the other in a regular pattern. Maize with opposite leaves phyllotaxis throughout their life cycle and also initiating ears in opposite pairs is very rare. As an aberrant mutant, it is of great theoretical and practical use in the study of the genetics, phylogeny, plant physiology, taxonomy and breeding of maize. The plant materials are also a precious genetic source for various germplasms in Zea mays. Galinat (1971) and Jackson et al. (1994) described a recessive maize mutant, abphyll, which has decussate phyllotaxy with leaves initiated in opposite pairs. The abphyll gene was mapped using the restriction fragment length polymorphism (RFLP) probe UMC34 to the short arm of chromosome 2. Subsequently, they studied the morphogenetic causation and physiological structure of the mutant (Jackson and Hake, 1999; Giulini et al., 2004).

In 1990, we obtained one opposite leaf maize mutant, Huang 48 (derived from the progeny of Huangzao $4 \times 478$ ), with $30 \mathrm{Kev} \mathrm{N}+$ ion radiation (Cai et al., 1992). After selection of several generations, it exhibited a steady opposite decussate phyllotaxy plant (Figure 1a). During the periods of 1991 to 1996, alternate phyllotaxy maize line H53, as backcross parent, was used to construct OP maize NILs H14D/H53 through continuous backcrossing and selfpollination. Along with opposite leafing genes transferred to maize, general combined ability of yield was decreased (Cai et al., 2005, 2006), but the grain quality characters in OP maize were higher than that in normal maize, especially regarding the content of oil and starch.

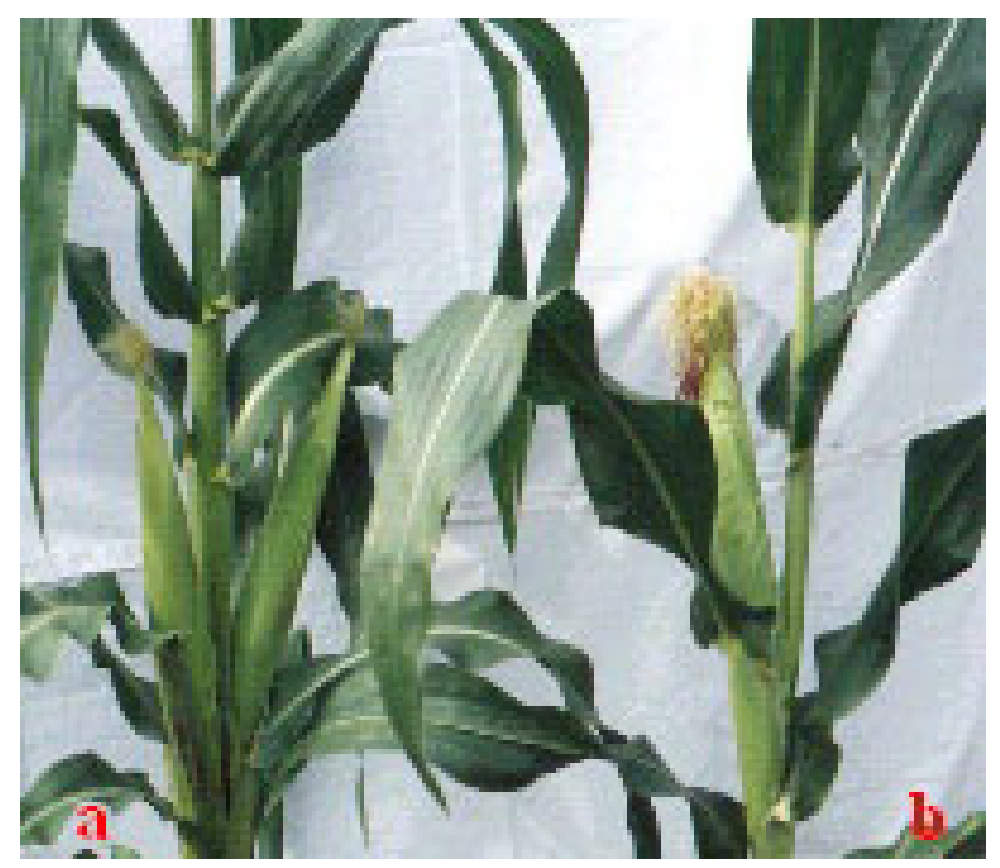

Figure 1. Shape of the OP mutant (showing decussate phyllotaxis and two prominent ears (a) and normal adult maize (b)). 
To improve MAS breeding of OP maize and provide the basis for the cloning of the OP genes, we located the OP loci using SSR molecular markers based on genetic analysis of NIL H14D/H53. Results from this study were used to breed hybrid varieties of OP maize, especially rapidly screening for alternate phyllotaxy maize lines including opposite leafing genes. Their hybrids had higher yield and better quality. This would be useful to explore the molecular mechanism of OP trait and uncover the possible connections between the discoverable opposite leafing genes. On the other hand, the use of SSR markers as an effective method for the localization of novel genes (Mohammadi et al., 2002) shows considerable variation, high polymorphisms and stability (Selvi et al., 2003; Budak et al., 2004; Frary et al., 2005). Presently, a microsatellite maize mapping consisting of more than five thousand SSR markers has been constructed by the University of Missouri, covering all the 10 chromosomes of maize. Following the development of high-density SSR markers, they have been widely used for locating correlative genes in maize, such as resistant genes to Southern rust (Liu et al., 2003), resistant genes to Setosphaeria turcica (Simcox and Bennetzen, 1993), and so on. In the present study, the opposite leafing genes $O p p-1$ and $O p p-2$ were also mapped using SSR markers.

\section{MATERIAL AND METHODS}

\section{Plant materials}

NIL H14D/H53 was produced from 1994 to 1998 . H14D $\left(\mathrm{P}_{1}\right)$ and $\mathrm{H} 53\left(\mathrm{P}_{2}\right)$ were planted in 2002 on the farm of Anhui Agricultural University and then used to produce the $\mathrm{F}_{1}, \mathrm{~F}_{2}$ and $\mathrm{BC}_{1}$ populations. H53 was crossed with $\mathrm{H} 14 \mathrm{D}$ as the maternal parent. Seeds from $\mathrm{F}_{1}$ plants were collected to develop the $\mathrm{F}_{2}$ family. Six $\mathrm{F}_{2}$ families and one $\mathrm{BC}_{1}$ population derived from the parent crosses were used for genetic analyses. One of the $\mathrm{F}_{2}$ populations consisting of 441 individuals was used for molecular mapping.

\section{Genomic DNA extraction}

Genomic DNA from H14D and H53 inbred lines and $441 \mathrm{~F}_{2}$ individual plants was processed for SSR marker analysis. DNA was extracted from the youngest leaves by the mini-extraction method with CTAB according to the standard procedure (McCouch et al., 1988).

\section{Establishment of parents' DNA pools}

In order to reduce error from individuals, genomic DNA was extracted from each of twenty plants of H14D and H53 inbred lines. We mixed the same amount of DNA provided from individuals. Next, opposite and alternative leafing parents' DNA pools were established and they were used as template DNA for the SSR polymorphism survey.

\section{SSR protocol}

The sequences of SSR primer sets used in this study came from the Maize Genetics and Genomic Database (http://www.maizegdb.org/cite.php and http://www.agron.missouri. 
edu/bady/ssr.html). PCR amplification and microsatellite analysis were carried out according to published procedures (Liu et al., 1996; Ramsay et al., 2000). A 25- $\mu$ L PCR mixture contained $120 \mathrm{ng}$ genomic DNA (parents or $\mathrm{F}_{2}$ individuals), $0.3 \mu \mathrm{M}$ of each primer, $2.5 \mu \mathrm{L} 10 \mathrm{X}$ reaction buffer $\left(250 \mathrm{mM}\right.$ Tris with $\left.20 \mathrm{mM} \mathrm{MgCl}_{2}\right), 1.5 \mathrm{U} \mathrm{Taq}$ polymerase and $200 \mu \mathrm{M}$ dNTPs. PCR was performed in a Biometra-96 gradient PCR instrument and subjected to 35 cycles of denaturation $\left(1 \mathrm{~min}\right.$ at $\left.94^{\circ} \mathrm{C}\right)$, annealing $\left(1 \mathrm{~min}\right.$ at $\left.50 \sim 60^{\circ} \mathrm{C}\right)$ and extension $\left(2 \mathrm{~min}\right.$ at $\left.72^{\circ} \mathrm{C}\right)$, with a final extension at $72^{\circ} \mathrm{C}$ for $5 \mathrm{~min}$. PCR products were separated by electrophoresis on $5 \%(w / v)$ agarose gels (Lucey et al., 1997) stained with ethidium bromide.

\section{Linkage analysis}

MAPMAKER version 3.0b was used for genetic mapping and linkage analysis (Lander et al., 1987; Lincoln et al., 1992). The linkage map was constructed on the basis of a LOD threshold of 3.0 and maximum Haldane distance of $50 \mathrm{cM}$. Recombination frequencies were converted to genetic distances based on the method of Kosambi (1944).

\section{RESULTS}

\section{Genetic analysis}

The statistics of parents and their progeny performances (Table 1) showed that both P1 (H14D) and $F_{1}$ plants exhibited $O P$ traits, and seeds from each $F_{1}$ plants were collected to generate the $\mathrm{F}_{2}$ family separately. The segregation of the $\mathrm{F}_{2}$ population agreed with the ratio of 9:7 of opposite to alternate phyllotaxis plants, and the $\chi^{2}$ values were between 0.01 and 0.54 $\left(\chi^{2}=0.01 \sim 0.54<\chi 20.05=3.84\right)$. The character performance of the $\mathrm{BC} 1$ population according to the ratio of opposite to alternate phyllotaxis plants was $1: 3\left(\chi^{2}=0.28<\chi^{2} 0.05=3.84\right.$. Mendelian genetic analysis indicated that the opposite leafing phenotype was controlled by two genes with complete dominance and independent and mutually complementary relation, so we named the two OP dominant genes Opp-1 and Opp-2.

Table 1. Segregation of the opposite and alternate phyllotaxis phenotypes in $\mathrm{F}_{2}$ plants and $\mathrm{BC}_{1}$ family.
\begin{tabular}{lccccc}
\hline Material & Total plants & Opposite plants & Alternate plants & Theoretical ratio & $\chi^{2}$ value \\
\hline $\mathrm{P}_{1}(\mathrm{H} 14 \mathrm{D})$ & 87 & 87 & 0 & & \\
$\mathrm{P}_{2}(\mathrm{H} 53)$ & 93 & 0 & 93 & & \\
$\mathrm{~F}_{2}$ & 120 & 120 & 0 & $9: 7$ & 0.01 \\
$\mathrm{One}_{\text {ne }} \mathrm{F}_{2}$ family & 441 & 247 & 77 & $1: 3$ & 0.28 \\
$\mathrm{~B}_{2}$ & 99 & 22 & & & \\
\hline
\end{tabular}

\section{Mapping of the Opp-1 and Opp-2 genes}

A total of 105 microsatellite markers throughout the maize genome were used to screen parents, and seven pairs distributed on the first, second, eighth and ninth chromosomes of maize showed polymorphism (Figure 2). The polymorphism frequency was $6.67 \%$ with high stability and good reproducibility. This low level of polymorphism could be attributed to the similar genetic background in the NIL H14D/H53. Because the OP trait was controlled by 
two dominant genes with mutually complementary relationship, it was difficult to distinguish the two different genotypes (Opp-1_opp-2opp-2 and opp-1opp-1Opp-2_) in the $\mathrm{F}_{2}$ alternate phyllotaxis plants. Therefore, high quality genomic DNAs were extracted and sorted into two DNA pools, and alternate pool performed the same background as the opposite pool. The polymorphic SSR markers were then used to test the $\mathrm{F}_{2}$ progeny, and some of the alternate phyllotaxis individual plants revealed that only the SSR markers umc2094 and bnlg1831 were linked to the two OP dominant genes, respectively, according to the LOD principle (Figures 3 and 4). It is difficult to locate genes only using OP plants. In this study, we selected 194 alternate phyllotaxis plants for mapping analysis. The results showed that different banding patterns were exhibited in the individual plants. Linkage analysis using MAPMARKER/EXP indicated that umc2094 linked to Opp-1 at a distance of $6.7 \mathrm{cM}$ on Bin2.01 of LG2 and bnlg1831 linked to Opp-2 at a distance of $6.1 \mathrm{cM}$ on Bin2.06 of LG2.

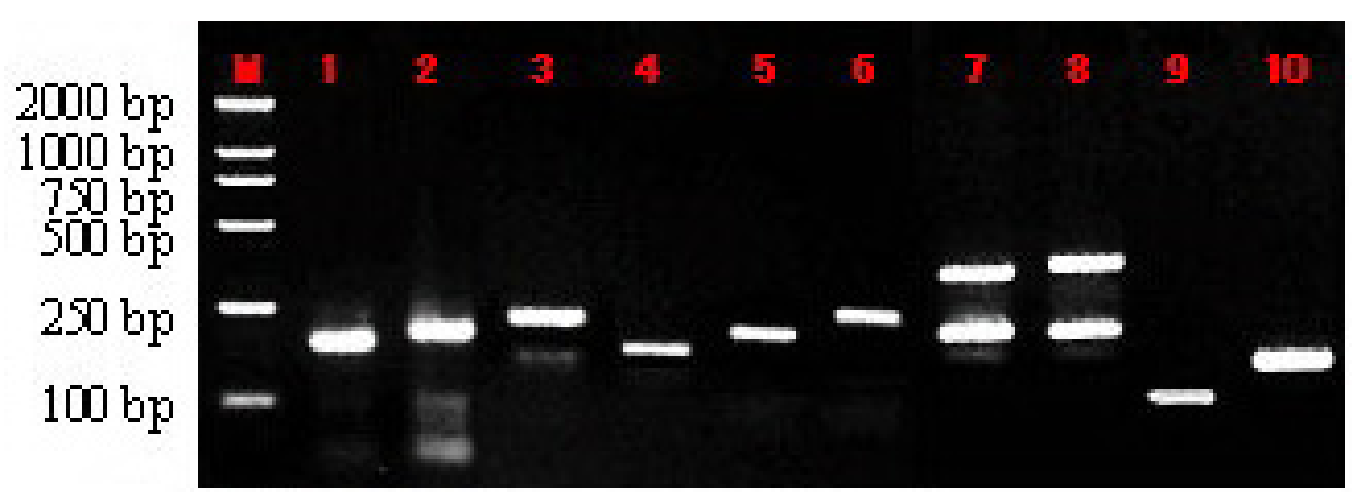

Figure 2. Comparison of the SSR polymorphisms in the parents' DNA pools. The DNA pools were analyzed using the SSR markers bnlg1720, bnlg1831, umc1627, bnlg128 and umc2094. The panel shows the analysis of the parent H14D DNA pools (lanes 1, 3, 5, 7 and 9) and H53 DNA pools (lanes 2, 4, 6, 8 and 10) with bnlg1720 (lanes 1 and 2), bnlg1831 (lanes 3 and 4), umc1627 (lanes 5 and 6), bnlg128 (lanes 7 and 8) and umc2094 (lanes 9 and 10$) . \mathrm{M}=$ DL2000 marker lane.

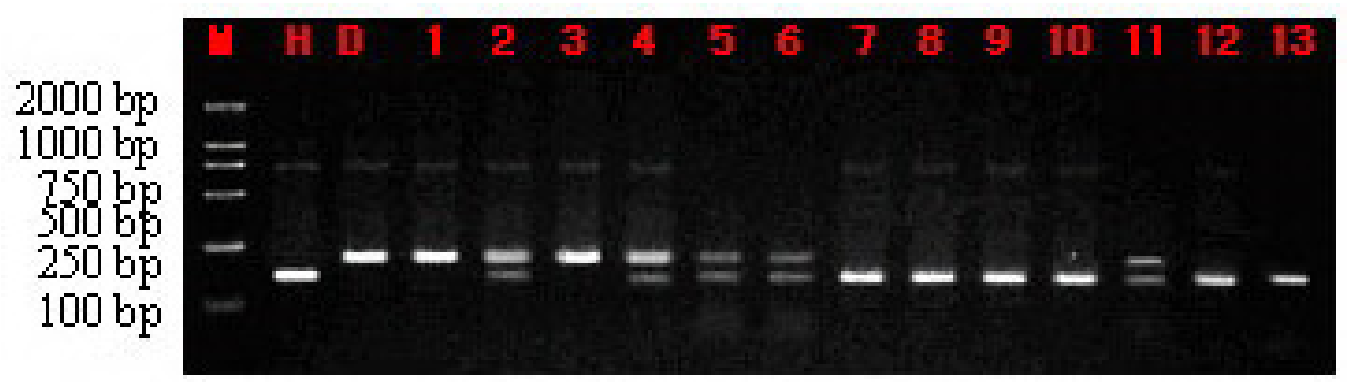

Figure 3. PCR analysis of parents' pools and $F_{2}$ individuals with SSR bnlg1831. M = DL2000 marker lane; $H$, parent H53 DNA pool; D, parent H14D DNA pool; lanes 1-6, $\mathrm{F}_{2}$ opposite phyllotaxis individuals; lanes 7-13, $\mathrm{F}_{2}$ alternate phyllotaxis plants. 


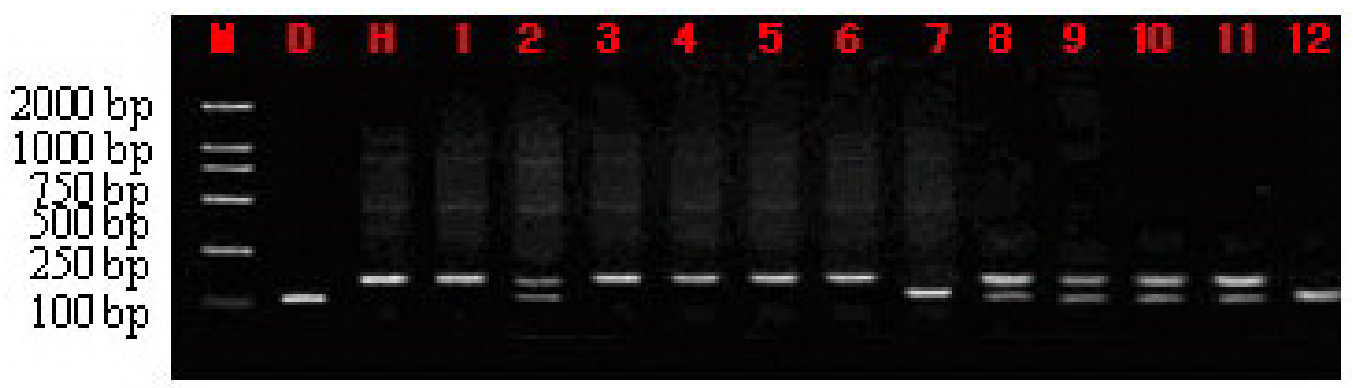

Figure 4. PCR analysis of parents' pools and $F_{2}$ individuals with SSR umc2094. M = DL2000 marker lane; D, parent H14D DNA pool; $\mathrm{H}$, parent $\mathrm{H} 53$ DNA pool; lanes 1-6, $\mathrm{F}_{2} \mathrm{OP}$ individuals; lanes $7-12, \mathrm{~F}_{2}$ alternate phyllotaxis plants.

\section{Further location of the $O p p-1$ and $O p p-2$ genes}

Twenty-six microsatellite markers near umc2094 and bnlg1831 were selected to analyze the parents and $\mathrm{F}_{2}$ individual plants. Polymorphisms in bnlg1092, bnlg1887 and umc1028 were detected between the two parents. Analysis of the individual plants indicated that bnlg1092 and umc1028 markers linked to Opp-1 and Opp-2, respectively. Among the 194 plants, 41 plants were recombinant for bnlg1029, and 6 plants for umc1028. Marker bnlg1092 linked to Opp-1 with a genetic distance of $12.2 \mathrm{cM}$, and umc 1028 linked to $O p p-2$ with a genetic distance of 1.9 cM. Furthermore, all the recombinant plants were different compared to umc2094, bnlg1831, bnlg1029 and umc1028, indicating that the four markers flanked the two OP genes, respectively (Figure 5). From the genetic map of maize LG2, Opp-1 and Opp-2 are located in Bin2.01 and Bin2.06, respectively. These bins are separated by a genetic distance of $331 \mathrm{cM}(>50 \mathrm{cM})$, and therefore, $O p p-1$ and $O p p-2$ are independent with mutual complementarity.

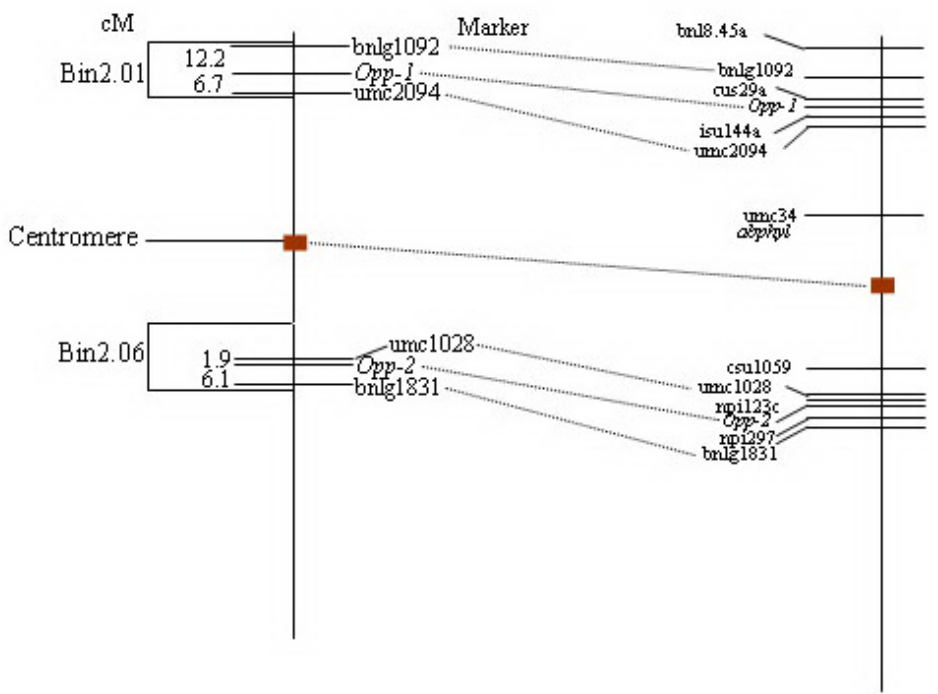

Figure 5. SSR linkage map of $O p p-1$ and $O p p-2$ with the surrounding SSR and RFLP markers compared to the map of maize LG2. 


\section{DISCUSSION}

Jackson and Hake (1999) located a recessive gene abphyll which regulated the OP phenotype in LG2 with RFLP markers. We also obtained one OP mutant with ion radiation. However, genetic analysis showed that our material was different compared to the abphyll OP mutant. We mapped two dominant opposite leafing genes in the Bin2.02 and Bin2.06 of maize genome with SSR markers. It is obvious that the control of opposite leafing trait was very complex, depending on multiple loci and/or genes. Different maize mutant materials, derivational methods and screening techniques could produce different gene locus mutations and different mutants.

Recently, we have developed a powerful strategy for genetic and physical mapping of the functional genes of maize using the publicly available genetic resources (Xie et al., 2002). We have adopted this strategy to finely define genetic and physical positions of the novel OP gene, Opp-1 and Opp-2. SSR markers were scarce in the Opp-1 region, and SSR markers are much more in the Bin2.06 region containing Opp-2 whereas exhibiting less polymorphism. Thus, the closest distances identified in this study were just $6.7 \mathrm{cM}$ and $1.9 \mathrm{cM}$ for the umc2094-Opp-1 and umc1028-Opp-2 linkages, respectively. These distances are far for the purpose of map-based cloning of the OP genes. It is necessary to identify additional nearby molecular markers to more precise locations. According to the maize genetic map from the Maize Genetics and Genomic Database (2004), there are some RFLP markers, such as csu29 and isu144a, in the regions of umc2094 and bnlg1092, and some other markers, such as npi123c and npi297, are near the Opp-2 region (Figure 5). More SSR markers will be also added to the SSR-sparse regions of the maize genetic map with the development of the maize genomic project (Sharopova et al., 2002). Thus, based on the SSR markers we have identified in this region, the application of different types of molecular markers may serve to localize the two OP genes more precisely, even including co-isolated markers. Thus, it will not only further improve MAS efficiency but also ultimately increase the possibility of cloning.

The purpose of searching linkage SSR markers with the two OP genes is to identify molecular "tags" for MAS breeding of the OP maize and cloning of the opposite leafing genes. Alternate phyllotaxis maize with OP genes has high general combined abilities and heterosis effects in yield and grain quality, but it is difficult to judge one alternate phyllotaxis maize containing one OP gene or not from the phenotype. It is possible to screen multi-genes according to general breeding methods, and the workload would be extremely large and hard. We can process the MAS of OP genes in the alternate phyllotaxis inbred lines rapidly and effectively with the linkage SSR markers. It will provide a valid way for OP maize hybrid breeding and establish a firm basis for more heterosis.

\section{ACKNOWLEDGMENTS}

Research supported by the National 863 Program of China (\#2006AA10Z1B4 and \#2008AA10Z408) and the Key Project of Chinese Ministry of Education (\#NO206065).

\section{REFERENCES}

Budak H, Shearman RC, Parmaksiz I and Dweikat I (2004). Comparative analysis of seeded and vegetative biotype buffalograsses based on phylogenetic relationship using ISSRs, SSRs, RAPDs, and SRAPs. Theor. Appl. Genet. 
109: $280-288$

Cai LQ, Li Z and Zhu SW (2005). Analysis on heterosis and combining ability of yield characters in opposite maize. Acta Laser Biol. Sin. 14: 95-102.

Cai LQ, Cheng BJ and Li Z (2006). Analysis on heterosis and combining ability of grain quality characters in opposite maize. Acta Laser Biol. Sin. 15: 154-160.

Cai YP, Tao HZ and Cheng BJ (1992). Transpiration and photosynthetic characteristics of opposite maize. J. Anhui Agr. Univ. 23: 474-477.

Frary A, Xu Y, Liu J, Mitchell S, et al. (2005). Development of a set of PCR-based anchor markers encompassing the tomato genome and evaluation of their usefulness for genetics and breeding experiments. Theor. Appl. Genet. 111: 291-312.

Galinat WC (1971). Genetic investigation of a novel mutant of maize. Annu. Rev. Genet. 5: 447-478.

Giulini A, Wang J and Jackson D (2004). Control of phyllotaxy by the cytokinin-inducible response regulator homologue ABPHYL1. Nature 430: 1031-1034.

Jackson D and Hake S (1999). Control of phyllotaxy in maize by the abphyll gene. Development 126: 315-323.

Jackson D, Veit B and Hake S (1994). Expression of maize KNOTTED1 related homeobox genes in the shoot apical meristem predicts patterns of morphogenesis in the vegetative shoot. Development 120: 405-413.

Kosambi DD (1944). The estimation of map distances from recombination values. Ann. Eugen. 12: 172-175.

Lander ES, Green P, Abrahamson J, Barlow A, et al. (1987). MAPMAKER: an interactive computer package for constructing primary genetic linkage maps of experimental and natural populations. Genomics 1: 174-181.

Lincoln S, Daly M and Lander E (1992). Constructing Genetic Maps with Mapmarker/Exp 3.0. Whitehead Institute Technical Reports. 3rd ed. Whitehead Institute, Cambridge.

Liu ZW, Biyashev RM and Saghai Maroof MA (1996). Development of simple sequence repeat markers and their integration into a barley linkage map. Theor. Appl. Genet. 93: 869-876.

Liu ZX, Wang SC, Dai JR, Huang LJ, et al. (2003). Studies of genetic analysis and SSR linked marker location of gene resistance to Southern rust in inbred line P25 of maize. Yi Chuan Xue Bao 30: 706-710.

Lucey MJ, McColl SM and Manning FC (1997). Method to reduce the quantity of ethidium bromide required to stain DNA in agarose gels. Biotechniques 23: 780-782.

McCouch SR, Kochert G, Yu ZH, Wang ZY, et al. (1988). Molecular mapping of rice chromosomes. Theor. Appl. Genet. 76: 815-829.

Mohammadi SA, Prasanna BM, Sudan C and Singh NN (2002). A microsatellite marker based study of chromosomal regions and gene effects on yield and yield components in maize. Cell Mol. Biol. Lett. 7: 599-606.

Moore CWE (1964). Distribution of Grasslands. In: Grasses and Grasslands (Barnard C, ed.). Macmillan, London, 182205.

Ramsay L, Macaulay M, degli IS, MacLean K, et al. (2000). A simple sequence repeat-based linkage map of barley. Genetics 156: 1997-2005.

Selvi A, Nair NV, Balasundaram N and Mohapatra T (2003). Evaluation of maize microsatellite markers for genetic diversity analysis and fingerprinting in sugarcane. Genome 46: 394-403.

Simcox KD and Bennetzen JL (1993). The use of molecular markers to study Setosphaeria turcica resistance in maize. Phytopathology 83: 1326-1330.

Xie CX, Zhu SW and Cheng BJ (2002). Obtaining of SCAR markers of two dominant genes for opposite leaves and fruits trait of Zea mays. High Technol. Lett. 8: 38-41. 